\title{
UM POUCO ALÉM DOS TERRITÓRIOS: O DIREITO FUNDAMENTAL DOS POVOS INDÍGENAS A UMA EDUCAÇÃO DIFERENCIADA*
}

\author{
Paulo Fernando Soares Pereira ${ }^{\dagger}$ \\ Joaquim Shiraishi Neto:
}

\begin{abstract}
Estavam tão pouco acostumados a ouvirem o catecismo, a assistirem à Missa, e outros semelhantes exercícios de um missionário, que fugiam, quando este lhes mostrava o seu crucifixo de latão; barbaridade, que pouco a pouco se foi vencendo, com ajuda do mesmo Senhor.
\end{abstract}

[Trecho de um Anal, de 1759, mencionado por Alexandre Rodrigues Ferreira, em sua Viagem Filosófica, p. 178]

RESUMO: Este trabalho de pesquisa tem como objetivo analisar a existência de um direito à educação diferenciada dos povos indígenas, sob a égide do ordenamento jurídico brasileiro. Discute-se, de forma inicial, a questão da dominação através do sistema educacional, no qual uma educação com objetivos universalizantes pode sufocar os modos de vida e os saberes tradicionais dos povos indígenas. Em seguida, discute-se, no contexto da Constituição Federal de 1988, a existência de um direito à educação diferenciada desses povos, que lhes garanta a oportunidade de transmissão de seus conhecimentos e tradições através de um sistema de ensino que respeite o direito às suas diferenças culturais, questionando-se o discurso jurídico que monopoliza o debate dos direitos dos povos indígenas em torno da questão dos territórios. Para além desse direito, devemos considerar os direitos culturais, especificamente, a educação.

PALAVRAS-CHAVE: Povos indígenas; Novos direitos; Educação diferenciada.

\section{A LITTLE BEYOND RESERVATION LAND: THE INDIANS FUNDAMENTAL RIGHT TO A DIFFERENTIATED EDUCATION}

\footnotetext{
* Artigo recebido em 14/03/2015 e aprovado em 29/03/2016.

† Mestre pelo Programa de Pós-Graduação em Direito e Instituições do Sistema de Justiça (PPGDIR/UFMA). Procurador Federal com exercício no Estado do Maranhão. Professor Universitário junto ao Departamento de Direito da Faculdade Estácio São Luís.

¥ Possui mestrado em Desenvolvimento Sustentável do Trópico Úmido pela Universidade Federal do Pará (1997) e doutorado em Direito pela Universidade Federal do Paraná (2004). Atualmente, é professor visitante da Universidade Federal do Maranhão, vinculado ao Programa de Pós-graduação em Direito (PPGDIR-UFMA). É professor colaborador do Mestrado Profissional em Gestão de Áreas Protegidas na Amazônia (MPGAP-INPA). Membro da Associação de Advogados Populares da Amazônia (AAPA). Tem experiência na área de Direito, com ênfase em Direitos Humanos, Direito Étnico, Direito Agrário e Ambiental, atuando principalmente nos seguintes temas: povos e comunidades tradicionais, movimentos sociais e conflitos sociais.
} 
ABSTRACT: The present research essay has the objective of analyzing the existence of an Indian differentiated education in brazilian legal system. First, the matter of domination through educational system is discussed, which universal objectives may stifle the ways of life and Indians traditional knowledge. Then, the Indians right to a differentiated education is approached, in 1988 Federal Constitution's context, ensuring these people the opportunity to transfer knowledge and traditions through an educational system that respects the rights to different culture, questioning the legal discourse that monopolizes the debate of Indians rights concerning Indians reserves. Beyond these right, cultural rights must be also considered, especially education.

KEY WORDS: Indians. New rights. Differentiated education.

\section{I - INTRODUÇÃO}

Os povos indígenas ${ }^{\S}$, após séculos de resistência, conseguiram, não de forma gratuita, o reconhecimento de diversos direitos na ordem jurídica brasileira, inclusive o direito básico de se autoreconhecerem como tais, pois, ainda hoje, travam batalhas para dizer que são povos indígenas ${ }^{* *}$.

No plano legislativo, a maior consagração foi a conferida pela Constituição Federal de 1988, que reconheceu aos mesmos a "sua organização social, costumes, línguas, crenças e tradições, e os direitos originários sobre as terras que tradicionalmente ocupam" (art. 231, caput).

Em que pese o rol de novos direitos dos povos indígenas, a discussão em torno dos mesmos, após 20 (vinte) anos de Constituição, não raras vezes, tem se resumido à questão da tutela (nas décadas de 80 a 90, a tutela aparecia forte) e dos direitos territoriais. Não se desconhece ou se faz pouco caso do direito ao território, pois o mesmo é essencial para a reprodução física dos povos indígenas ${ }^{\dagger \dagger}$.

\footnotetext{
§ A utilização do termo "povos indígenas" é decorrente da Convenção 169 da Organização Internacional do Trabalho - OIT, que substituiu 'população' por 'povos', qualificação cujos efeitos foram, entretanto, cuidadosamente limitados. Na definição desses povos, não é feita mais a menção a um estágio de desenvolvimento 'menos avançado', sendo que o espírito de numerosas disposições da mesma é claramente inspirado por análises pluralistas (ROULAND, 2004).

** "Comunidades indígenas são pois aquelas que, tendo uma continuidade histórica com sociedades précolombianas, se consideram distintas da sociedade nacional. E índio é que pertence a uma dessas comunidades indígenas e é por ela reconhecido. Parece simples. Só que se conserva às sociedades indígenas o direito soberano de decidir quem lhes pertence: em última análise, é es se direito que a FUNAI lhes quer retirar. Claro está que índio emancipado continua índio e, portanto, detentor de direitos históricos. Mas tal não parece ser a interpretação da FUNAI, que lava as mãos de qualquer responsabilidade em relação aos índios emancipados" (CUNHA, 2013, p. 103).

$\dagger$ "O direito a terra, entendida como o espaço de vida e liberdade de um grupo humano, é a reivindicação fundamental dos povos indígenas brasileiros e latino americanos [...] É evidente que a questão da territorialidade
} 
Revista da Faculdade de Direito-RFD-UERJ - Rio de Janeiro, n. 31, jun. 2017

Contudo, caso, nos planos social, político e acadêmico, deixe-se de lado a problemática em torno de outros direitos, igualmente, relevantes e imprescindíveis à reprodução desses povos (como a educação diferenciada), dá-se margem para se anular a conquista do direito aos territórios, haja vista que esse direito, para ser bem exercido e proporcionar a sobrevivência cultural dos povos indígenas, é dependente dos demais; em outras palavras, a interdependência e complementariedade que caracterizam esses direitos fundamentais devem ser "levadas à sério", sob pena de se violar os direitos consagrados a esses povos.

Nesse contexto, a Constituição tratou de garantir o direito à educação diferenciada, ao determinar que as comunidades terão garantidos o direito de utilização das línguas maternas $\$$ e processos próprios de aprendizage $\mathrm{m}^{\S}$.

Pretende-se, dessa forma, verificar em que consiste, juridicamente, a existência de um direito à educação diferenciada dos povos indígenas brasileiros, a partir das disposições introduzidas pela Constituição Federal de 1988 (arts. 210, §2º , e 231, caput), em harmonia com a Convenção 169 (arts. 26 a 31), da Organização Internacional do Trabalho, sobre Povos Indígenas e Tribais, incorporada ao ordenamento brasileiro através do Decreto Legislativo $\mathrm{n}^{\circ}$ 146/2002 e Decreto no 5.051/2004, e demais legislação de regência, principalmente o Decreto $\mathrm{n}^{\circ}$ 6.861, de 27 de maio de 2009, que dispõe sobre a Educação Escolar Indígena, definindo seus objetivos (art. $2^{\circ}$ ) e sua organização em "Territórios Etnoeducacionais".

Tal preocupação se justifica em virtude de, ultimamente, os povos indígenas, conhecedores de seus direitos, têm levantado uma série de reivindicações (distribuição do investimento e do gasto, conteúdos curriculares e material didático adequados à realidade comunitária, qualidade do ensino, dever do Estado em formar de professores indígenas, concursos públicos exclusivos para professores indígenas, mestrados exclusivos para indígena

assume proporção da própria sobrevivência dos povos, um povo sem território, ou melhor, sem o seu território, está ameaçado de perder suas referências culturais e, perdida a referência, deixa de ser um povo" (SOUZA FILHO, 2004, p. 119-120).

\# Para a maioria dos comentadores do texto constitucional de 1988, não há o que se comentar em relação ao caput do art. 13 da Constituição, pois, para eles, há uma obviedade de que a língua portuguesa é o idioma oficial do Brasil. Todavia, esses autores se esquecem de que o uso da língua portuguesa foi imposto pelo Marquês de Pombal. No contexto de reconhecimento da diversidade social brasileira, necessita-se refletir sobre esses processos tidos como naturais. A esse respeito, remete-se a publicação organizada por Almeida (2007).

$\S \S$ A Constituição Federal dispõe: “Art. 210. Serão fixados conteúdos mínimos para o ensino fundamental, de maneira a assegurar formação básica comum e respeito aos valores culturais e artísticos, nacionais e regionais. [...] $\S 2^{\circ}-\mathrm{O}$ ensino fundamental regular será ministrado em língua portuguesa, assegurada às comunidades indígenas também a utilização de suas línguas maternas e processos próprios de aprendizagem”. 
etc.) $)^{* * *}$ que precisam ser analisadas sob uma ótica jurídica desprovida de preconceitos, pois, contraditoriamente ao plano legislativo, no qual existe farto material a respeito da educação, inclusive sobre a educação diferenciada dos povos indígenas, no plano acadêmico, a bibliografia jurídica disponível não é das mais generosas, o que tem dificultado a análise do ponto de vista do direito.

O fato descrito acima foi notado por Diogo Alfonso Iturralde Guerrero (2006), ao lembrar que o desenvolvimento da legislação, por si mesmo, não constitui evidência do grau de desenvolvimento e do êxito da educação diferenciada, sendo, unicamente, um indício do rumo que a resposta do Estado vem tomando e da existência - ou não - de bases jurídicas que contribuam para fazer com que esse direito seja mais passível de exigência. Ademais, não custa lembrar que o direito se encontra referido a um campo de disputas, onde há uma luta entre os interpretes para o "direito em dizer o direito" (BOURDIEU, 1989).

Nesse momento ímpar, faz-se necessário que o direito tenha o substrato teórico "adequado" para a análise das reivindicações dos povos indígenas, dentre elas o direito à educação diferenciada, agregando à discussão dos direitos territoriais, o direito à educação diferenciada.

O objetivo, portanto, do presente trabalho consiste em analisar a existência de um direito à educação diferenciada dos povos indígenas, sob a égide do ordenamento jurídico brasileiro, que tem o pluralismo como valor fundamental. Para tanto, organizou-se o texto da seguinte forma: a) Novos direitos na América Latina: da educação da dominação a uma educação do reconhecimento, em que se analisa o quanto o processo de educação foi utilizado como forma de dominação dos povos originários na América Latina, inclusive o papel que o direito representou nesse processo. As reflexões ambientadas no denominado "Novo Constitucionalismo" nos convidam a discussão permanente sobre os direitos culturais dos povos indígenas; b) $\mathrm{O}$ direito à educação diferenciada dos povos indígenas, no qual se analisa qual o significado jurídico desse direito diferenciado, abordando-se quais os limites práticos dessa diferenciação.

\footnotetext{
*** GUERRERO, Diego Alfonso Iturralde. Direitos culturais indígenas e educação intercultural bilíngue - a situação na América Central. In: HERNAIZ, Ignacio (org). Educação na diversidade: experiências e desafios na educação intercultural bilíngüe. Brasília: UNESCO, Secad/MEC, 2006, p. 117; Cf. PROJETO PEDAGÓGICO DO CURSO DE GESTÃO TERRITÓRIAL. Núcleo Insikiran de Formação Superior Indígena da Universidade Federal de Roraima (UFRR). Boa Vista (RR), s/d, p. 3.
} 


\section{II - NOVOS DIREITOS NA AMÉRICA LATINA: DA EDUCAÇÃO DA DOMINAÇÃO A UMA EDUCAÇÃO DO RECONHECIMENTO}

Para iniciar o debate a respeito dos novos direitos ${ }^{\dagger \dagger \dagger}$ que permeiam a América Latina , em especial o Brasil, faz-se necessário discutir as questões do direito à diferença ${ }^{\$ \S \S}$, que perpassa pelo debate em torno das ideias de multiculturalidade ${ }^{* * *}$ e interculturalidade, para, em seguida, discutir-se o direito à educação diferenciada dos povos indígenas.

Catherine Walsh (2012) lembra que a multiculturalidade e a pluriculturalidade são termos descritivos que servem para caracterizar a situação diversa e indicar a existência de múltiplas culturas em um determinado lugar, disseminando seu reconhecimento, tolerância e respeito; a interculturalidade, ao contrário, ainda não existiria, pois é algo por construir, indo além do respeito, a tolerância e o reconhecimento da diversidade ${ }^{\dagger i \dagger i}$, seria um processo e

\footnotetext{
††† Na América Latina, os povos indígenas têm adquirido um espaço e um papel político inédito, passando a intervir, diretamente, na vida política, em um contexto novo em que as demandas nacionais costumam ser articuladas através da interação entre as organizações indígenas e os foros internacionais (GIRAUDO, 2007).

赫 "Mais uma vez os Estados nacionais latino-americanos reafirmaram suas semelhanças. Os sistemas jurídicos constitucionais, antes fechados ao reconhecimento da pluralidade e da multietnicidade, foram reconhecendo, um a um, que os países do continente têm uma variada formação étnica e cultural, e que cada grupo humano que esteja organizado segundo sua cultura e viva segundo a sua tradição, em conformidade com a natureza da qual participa, tem direito à opção de seu próprio desenvolvimento. Estes novos direitos têm como característica o fato de sua titularidade não ser individualizada. Não são fruto de uma relação jurídica, mas apenas de uma garantia genérica, que deve ser cumprida e que, no seu cumprimento, acaba por condicionar o exercício dos direitos individuais. Isto quer dizer que os direitos coletivos não nascem de uma relação jurídica determinada, mas de uma realidade, como pertencer a um povo ou formar um grupo que necessita ou deseja ar puro, água, florestas e marcos culturais preservados, ou ainda garantias para viver em sociedade, como trabalho, moradia e certeza de qualidade dos bens adquiridos. Esta característica os afasta do conceito de direito individual concebido em sua integralidade na cultura contratualista ou constitucionalista do século XIX, porque é um direito sem sujeito. Ou, dito de maneira que parece ainda mais confusa para o pensamento individualista, é um direito onde todos são sujeitos. Se todos são sujeitos do mesmo direito, todos dispõem dele, mas ao mesmo tempo ninguém pode dele dispor, contrariando-o, porque a disposição de um seria a violação do direito de todos os outros" (SOUZA FILHO, 2003, p. 93-94).

\$§ "Em um plano geral, nenhum dos direitos dos povos autóctones está excluído do direito à diferença, uma vez que todo esforço atual do direito internacional consiste em preservar suas especificidades organizan do-as de maneira que permaneçam toleráveis para os Estados e para as sociedades dominantes. Entretanto, uma noção parece particularmente importante: aquela dos direitos culturais, na medida em que os autóctones reivindicam prioritariamente o respeito por suas culturas, no sentido antropológico do termo, exigência essa constantemente reafirmada nos instrumentos internacionais" (ROULAND, 2004, p. 492-493).

**** Boaventura de Souza Santos e João Arriscado Nunes (2003) lembram que a terminologia é um conceito contestado, mas, ao final, reconhecem, apesar das críticas, que a mesma se generalizou como modo de designar as diferenças culturais em um contexto transnacional e global, o que não significa, por outro lado, que tenham sido superadas as contradições e tensões internas apontadas pelos críticos, pois, de fato, a expressão pode continuar associada a conteúdos e projetos emancipatórios e contra-hegemônicos ou a modos de regulação das diferenças no quadro do exercido da hegemonia nos Estados -nação.

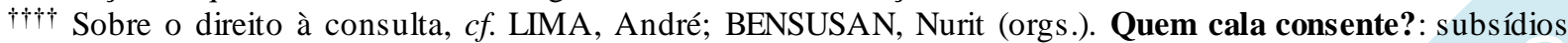
para a proteção dos conhecimentos tradicionais. São Paulo: Instituto Socioambiental, 2003.
} 
projeto social e político dirigido a construção de sociedades, relações e condições novas e distintas de vida $\$+$.

No entanto, a multiculturalidade e pluriculturalidade podem ser tornadas invisíveis através da violência simbólica, com a astúcia imperialista, que consiste em universalizar particularismos ligados a uma tradição histórica singular, fazendo que essas tradições não sejam reconhecidas como tal, neutralizando determinado contexto histórico resultante da circulação internacional de textos e do correspondente esquecimento de suas condições históricas, produzindo uma aparente universalização, valendo-se para tanto da violência simbólica, que é aquela que é imposta sem que seja percebida (BOURDIEU; WACQUANT, 2005).

Nesse contexto, parece ter havido o uso violência simbólica para dominar culturalmente os povos indígenas através do aspecto universalizante do processo educacional, com a homogeneização da língua portuguesa ${ }^{\S \S \S}$.

De forma astuta, procurou-se dar invisibilidade às tradições culturais indígenas, ao se estabelecer que a língua do povo dominante seria a língua oficial do país, a qual através do processo de educação, seria difundida para todos os povos indígenas, sob o discurso de existência de uma "comunhão nacional"*****, que deveria ser comungada por todos.

Assim, o que está em jogo é o poder de imposição do mundo social através de critérios pretensamente científicos, que impõem ao conjunto do grupo uma unidade e

H\# "Enquanto o multiculturalismo sustenta a produção e administração da diferença dentro da ordem nacional voltada para a expansão do neoliberalismo, a interculturalidade, entendida desde sua significação pelo movimento indígena, aponta trocas radicais a esta ordem. Seu objetivo não é simplesmente reconhecer, tolerar, tampouco incorporar o diferente dentro da matriz e estruturas estabelecidas. Pelo contrário, é implodir desde a diferença nas estruturas coloniais do poder como desafio, proposta, processo e projeto; é fazer reconceituar e refundar estruturas que põem em cena e em relação equitativa lógicas, práticas e modos culturais diversos de pensar, atuar e viver. Assim, sugere um processo ativo e permanente de negociação e interrelação de onde o próprio e particular não percam sua diferença, mas que tenham oportunidade e capacidade para aportar desta diferença a criação de novas compreensões, convivências, colaborações e solidariedades. Por isso, a interculturalidade não é algo feito, mas algo em permanente caminho, insurgência e construção" (WALSH, 2012, p. 119).

§§§ A Constituição Federal atual determina, por exemplo, em seu art. 13, que "A língua portuguesa é o idioma oficial da República Federativa do Brasil".

***** Veja-se o Estatuto do Índio, que dispõe: Art. $1^{\circ}$ Esta Lei regula a situação jurídica dos índios ou silvícolas e das comunidades indígenas, com o propósito de preservar a sua cultura e integrá-los, progressiva e harmoniosamente, à comunhão nacional. [...] Art. $2^{\circ}$ Cumpre à União, aos Estados e aos Municípios, bem como aos órgãos das respectivas administrações indiretas, nos limites de sua competência, para a proteção das comunidades indígenas e a preservação dos seus direitos: [...] VI - respeitar, no processo de integração do índio à comunhão nacional, a coesão das comunidades indígenas, os seus valores culturais, tradições, us os e costumes; [...]VIII - utilizar a cooperação, o espírito de iniciativa e as qualidades pessoais do índio, tendo em vista a melhoria de suas condições de vida e a sua integração no processo de desenvolvimento; ;Grifou-se]. 
consenso, utilizando-se a língua portuguesa como importante instrumento para a construção dessa unidade, tanto que a mesma se encontra localizada no capítulo que diz respeito à nacionalidade (SHIRAISHI NETO, 2007).

O processo educacional em sua forma tradicional constitui uma das maiores formas de dominação ${ }^{\dagger \dagger i \dagger}$, pois através dele podem se difundir preconceitos legitimadores de um sistema conservador. A escola se mostra um instrumento conservador, transmissor de uma cultura aristocrática, que o sistema de ensino transmite e exige, sendo, aliás, tradicional a visão segundo a qual o sistema escolar é visto como um fator de mobilidade social, segundo a ideologia de uma 'escola libertadora'; no entanto, ao contrário, tudo tende a mostrar que o sistema de ensino é um dos fatores mais eficazes de conservação social, pois fornece a aparência de legitimidade às desigualdades sociais e sanciona a herança cultural e dom social tratado como dom natural, pois a igualdade formal que pauta a prática pedagógica serve como máscara e justificação para a indiferença no que diz respeito às desigualdades reais diante do ensino e da cultura transmitida (BOURDIEU, 1999).

Sob o signo dessa educação supostamente igualitária e libertadora do atraso, os povos indígenas, no Brasil, desde o início dos primeiros contatos, foram vítimas de um processo de invisibilidade de suas identidades e os modos de transmissão de suas culturas sofreram preconceitos, muitos dos quais foram difundidos através do sistema de ensino. Mencione-se, por exemplo, que o estudo das sociedades tradicionais, até hoje, encontra certas dificuldades na Etnologia (CALDEIRA, 2000), tendo em vista que muitas vezes os primeiros relatos dos povos indígenas são permeados por preconceitos $\$+4+$, representando, em sua maioria, a 'visão do conquistador', que tenta passar a sua versão a respeito dos acontecimentos históricos, o que, evidentemente, vai diminuir o nível de reconhecimento de seus direitos na seara jurídica.

Como era voz corrente que os índios eram 'muito propensos à preguiça e a viver na inação', deveriam ser incitados ao trabalho pelos párocos e funcionários coloniais, a

\footnotetext{
$\lceil\dagger \dagger \dagger \dagger$ Não se pode esquecer que uma das maiores violações contra os direitos humanos consiste em impedir que uma cultura, um grupo ou determinados indivíduos, dentro de seus grupos ou culturas, que possam reivindicar sua idéia de dignidade, sejam impedidos por norma ou não criando condições para que seu respeito seja posto em prática (HERRERA FLORES, 2000), o que, no caso dos povos indígenas brasileiros, consistiu em impedir que os mesmos exercessem plenamente suas tradições, muitas das quais julgadas como antiquadas, ultrapassadas, atrasadas ou incompatíveis com o processo civilizatório, segundo o qual o povo dominante se julga superior às tradições dos povos tradicionais. O processo de invisibilidade das línguas e de transmissão das tradições culturais dos povos indígenas bem retrata esse quadro de dominação.

t+tł José de Ribamar Chaves Caldeira (2000, p. 26), nesse sentido, lembra que Maurício de Heriarte descrevia os Tupinambá maranhenses, como "falsos, covardes, traidores, carniceiros, cruéis".
} 
quem caberia estimular os 'aplicados' e ridicularizar os 'vadios'. E por fim, os 'ociosos incorrigíveis' deveriam ser enviados às casas de correção ou obrigados ao trabalho nas obras públicas. Entenda-se que, nas próprias palavras de Pombal, a 'ociosidade' era um vício não só da 'moral', mas também 'político' e, em decorrência, a recusa ao trabalho por parte dos índios significaria, em um limite, uma recusa mesmo à condição de vassalos (FARAGE, 1991, p. 45).

Nesse viés, em relação aos povos indígenas brasileiros, vítimas desse processo de "astúcia imperialista" de invisibilidade de suas identidades, têm-se como marco legal mais evidente o Estatuto do Índio (Lei n. 6001/1973), que, em sua apoteose hermenêutica, apresenta como alegoria principal o objetivo de integralizá-los a uma suposta comunhão nacional ${ }^{\S \S \S \S \S}$, terminologia abstrata e indefinida, mas de efeitos bastantes perceptíveis aos que sentiram a concretude de sua astúcia discursiva e jurídica.

Sob o ponto de vista acima, o Estatuto do Índio, sob a "astúcia imperialista", representou um exemplo de pilhagem do Estado de Direito, pois permitiu que tradições seculares fossem subjugadas pelos povos dominantes. Nesse sentido, uma definição bem ampla de 'pilhagem' seria a distribuição injusta dos recursos praticados pelos fortes à custa

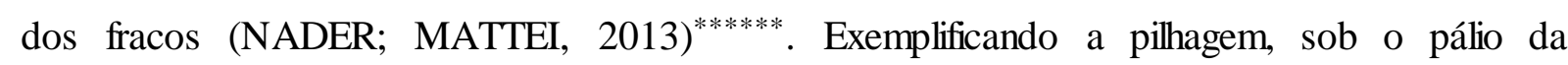
legislação, os povos indígenas, deixando suas terras e tradições, eram obrigados a se refugiar pelo Brasil adentro sob os empurrões do processo civilizador nacional, sob pena de permanecerem com a condição de renúncia a suas identidades.

Essa pilhagem do Estado de Direito, através da violência simbólica tem como função favorecer a opressão, mas, por outro lado, pode conceder aos oprimidos o poder que leva à contra-hegemonia (NADER; MATTEI, 2013). Essa contra-hegemonia, através do sistema de ensino, pode ser levada adiante mediante um processo educacional que permita aos povos indígenas o poder decisório sobre seus destinos, ou seja, que thes faculte decidir a respeito do modo de vida que pretendem seguir, o que representa o respeito à diferença cultural.

\footnotetext{
$\S \S \S \S$ Art. $1^{\circ}$ Esta Lei regula a situação jurídica dos índios ou silvícolas e das comunidades indígenas, com o propósito de preservar a sua cultura e integrá-los, progressiva e harmoniosamente, à comunhão nacional. [Grifou-se]

${ }^{* * * * * * *}$ Ao longo da história, o Estado de Direito tem sido fiel servidor da pilhagem, a tal ponto que alguns vestígios de concepções ocidentais de legalidade podem ser encontrados, pelo menos em nível superficial, em quase todos os sistemas jurídicos do mundo (NADER; MATTEI, 2013).
} 
Nesse contexto, os direitos humanos ${ }^{\dagger \dagger \dagger \dagger \dagger}$, inclusive o direito à diferença cultural, precisam ser descolonizados (CLAVERO, 2011), ou seja, precisam deixar de ser apenas um discurso monopolizado pela voz dos dominantes e deve pressupor uma dialética na qual os diferentes povos possam dialogar, permitindo-se que os povos dominados tenham seus modos de vida respeitados e que se permita que os mesmos participem de um projeto de reconstrução do Estado $\$+4+$, no qual não sejam meros receptáculos das tradições

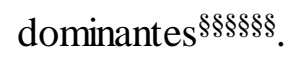

E deixar de ser receptáculo de um modo de vida dominante pressupõe que os povos indígenas tenham ao seu alcance um sistema de ensino que se adéque aos seus modos de vida e tradições, que não seja mera transmissão de conhecimento dissociado da realidade e que respeite as suas diferenças.

A educação diferenciada deve pressupor uma "pedagogia do oprimido" (FREIRE, 2014), na qual os povos indígenas, por eles mesmos, libertem-se da opressão do sistema educacional, em dois momentos distintos: a) primeiramente, os povos indígenas oprimidos terão que ter consciência da opressão e se comprometerão, pela práxis, com a sua transformação; b) em um segundo momento, transformando a realidade opressora, a pedagogia deixará de ser do oprimido e passará a ser pedagogia dos homens em permanente libertação.

Dessa maneira, com uma pedagogia libertadora, poderão os povos indígenas ter reconhecido o direito à diferença, o que lhes possibilitará a construção de educação diferenciada baseada em um saber prático e correspondente aos seus anseios culturais e a suas tradições, no qual o processo educacional não seja um mero repasse de ideias dominantes e opressoras.

\section{III - O DIREITO À EDUCAÇÃO DIFERENCIADA DOS POVOS INDÍGENAS}

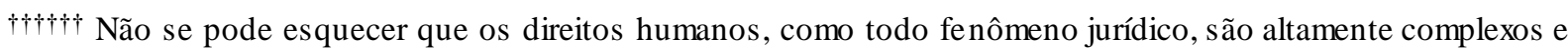
estão imbuídos por interesses ideológicos que não podem ser entendidos fora de sua perspectiva cultural (HERRERA FLORES, 2000).

H+tł Yrigoyen Fajardo (2011) propõe a ideia de reconstrução do Estado, com o reconhecimento de novos direitos, marcados pela diversidade e pelo pluralis mo, em que se reconheça a identidade e a diversidade cultural, desenvolvendo-se conceitos de uma nação multiétnica e multicultural.

\$§§§§ Yrigoyen Fajardo (2011) lembra que o pluralismo e a diversidade cultural podem se converter, dessa maneira, em princípios constitucionais que permitam refundar os direitos dos indígenas assim como os dos afrodescendentes e de outras comunidades tradicionais e incorporar, uma nova e larga lista de direitos indígen as, no que pode se incluir o direito à diferença que permitirá que esses povos tenham reconhecido o direito a uma educação diferenciada.
} 
A educação diferenciada, no plano jurídico, pressupõe o respeito ao direito à diferença. Nesse sentido, Nobert Rouland (2004) recorda que o princípio de direito à diferença foi afirmado pela UNESCO, em 1978, em um texto com abrangência geral: a Declaração sobre a raça e os preconceitos raciais (artigo 1), que dispõe:

1. Todos os seres humanos pertencem à mesma espécie e têm a mesma origem. Nascem iguais em dignidade e direitos e todos formam parte integrante da humanidade.

2. Todos os indivíduos e os grupos têm o direito de serem diferentes, a se considerar e serem considerados como tais. Sem embargo, a diversidade das formas de vida e o direito à diferença não podem em nenhum caso servir de pretexto aos preconceitos raciais; não podem legitimar nem um direito nem uma ação ou prática discriminatória, ou ainda não podem fundar a política do apartheid que constitui a mais extrema forma do racismo.

3. A identidade de origem não afeta de modo algum a faculdade que possuem os seres humanos de viver diferentemente, nem as diferenças fundadas na diversidade das culturas, do meio ambiente e da história, nem o direito de conservar a identidade cultural.

Em termos materiais, essa diferença sempre existiu no Brasil. Porém, por força da legislação, muitas vezes tenta-se tornar igualitário, conforme o discurso dominante, as diferenças reais. Nesse ponto, Darcy Ribeiro (2003) lembra que a sociedade e a cultura brasileira são conformadas como variantes da versão lusitana da tradição civilizatória européia ocidental, diferenciadas por coloridos herdados dos índios americanos e dos negros africanos $^{* * * * * * * *}$.

É nessa atmosfera de pluralismo étnico e respeito que a educação diferenciada deve ser compreendida. A educação é um direito de todos e constitui um direito social (art. $6^{\circ}$ c/c art. 205, da CF), representando o processo de reconstrução da experiência, sendo um atributo da pessoa humana, devendo ser um direito comum a todos (SILVA, 2003), o que inclui, evidentemente, os povos indígenas, integrantes da tradição pluralista do Brasil.

Nessa tradição pluralista, não se pode esquecer que os direitos dos povos indígenas são diversos e não exaustivos na Constituição

******* “O Brasil emerge, assim, como um renovo mutante, remarcado de características próprias, mas atado genesicamente à matriz portuguesa, cujas potencialidades insuspeitadas de ser e de crescer só aqui se realizariam plenamente. A confluência de tantas e tão variadas matrizes formadoras poderia ter resultado numa sociedade multiétnica, dilacerada pela oposição de componentes diferenciados e imiscíveis. Ocorreu justamente o contrário, uma vez que, apesar de sobreviverem na fisionomia somática e no espírito dos brasileiros os signos de sua múltipla ancestralidade, não se diferenciaram em antagônicas minorias raciais, culturais ou regionais, vinculadas a lealdades étnicas próprias e disputantes de autonomia frente à nação. As únicas exceções são algumas microetnias tribais que sobreviveram como ilhas, cercadas pela população brasileira. Ou que, vivendo para além das fronteiras da civilização, conservam sua identidade étnica” (RIBEIRO, 2003, p. 20).

 foram e são atores importantes de sua própria história, sendo crucial que estejam representados nas arenas 
conteúdo dos direitos indígenas, mas apenas sinalizou o que se denominaria de conteúdo mínimo, ou seja, todos aqueles direitos que decorrem direta ou indiretamente do reconhecimento e da proteção da 'organização social, costumes, línguas, crença e tradições, e os direitos originários sobre as terras' dos índios, suas comunidades e organizações (BARRETO, 2004). No entanto, em que pese isso, a discussão dos direitos indígenas, não raras vezes se restringe à questão territorial, que, conquanto de fundamental importância, é insuficiente por si só, para manter a sobrevivência cultural dos povos indígenas, sendo de se notar que a mera inserção de marcos nos territórios dos povos indígenas, por si só, não significa respeito aos direitos dos mesmos.

Com o exposto acima, não quer se desconhecer o direito ao território. Contrariamente, pretende-se demonstrar que o mesmo vai além da definição de cartas cartográficas. O direito aos territórios é o elemento essencial para que os povos indígenas possam usufruir os demais direitos que estão evidentes ou que estão prestes a ser descobertos ou construídos no texto constitucional. Não foi em vão que, nos Estados Unidos da América do Norte, a expulsão dos povos indígenas de suas terras foi o grande triunfo para dizimá-los.

\begin{abstract}
Impossível seria imaginar os terríveis males que acompanham tais emigrações forçadas. No momento em que os índios deixaram os seus campos ancestrais, estavam já esgotados e reduzidos. O território aonde vão fixar a sua morada está ocupado por populações que só vêem com hostilidade os recém-chegados. Por trás deles, vem a fome, à frente deles a guerra, por toda parte a miséria. A fim de escapar a tantos inimigos, dividem-se. Cada um deles procura isolar-se para encontrar furtivamente os meios de sustentar a sua existência, e vive na imensidade dos desertos com o proscrito no seio das sociedades civilizadas. O laço social, desde muito enfraquecido, rompe-se então. Para eles, já não havia uma pátria; em breve, não mais haverá um povo; mal restarão famílias; o nome comum se perde, a língua é esquecida, desaparecem os traços de origem. A nação deixou de existir. Vive apenas na lembrança dos antiquários americanos e só os conhecem alguns eruditos da Europa (TOCQUEVILLE, 1987, p. 249).
\end{abstract}

Alexis de Tocqueville (1987) alertava que não estava a carregar as tintas do seu texto $+1+1+t$, advertindo o quanto era calamitosa a situação dos povos indígenas dos

discursivas, para que não tenham seus direitos usurpados, até porque os povos indígenas têm reivindicações concretas, pois reclamam que se respeitem seus direitos coletivos sobre suas terras e o usufruto de suas riquezas, querem decidir sobre o seu futuro e participar das decisões que os afetam; querem, também, ver reconhecidos os seus direitos à organização e a canais de representação (CUNHA, 2013), is to é, os povos indígenas querem ser ouvidos por suas vozes próprias, dispensando o monopólio discursivo dos órgãos burocráticos do Estado, a exemplo da Fundação Nacional do Índio - FUNAI, permitindo-se que os movimentos indígenas tenham voz na construção das arenas políticas, para contrapô-los, com um enfoque local (MARTí I PUIG, 2011), às universalizantes interpretações dos povos dominantes.

$+++1+\$$ "Não gostaria que o leitor pudesse imaginar que estou carregando tintas deste quadro. Vi com meus próprios olhos muitas das misérias que acabo de descrever; contemplei males que me seria impossível retratar. 
Estados Unidos da América, ao terem suprimido o direito aos seus territórios, espoliados pela astúcia imperialista daquele então emergente Estado.

Aliás, o Estado, a depender de seus interesses econômicos e políticos, utilizase da questão das posses indígenas para sustentar um discurso jurídico que se adéque aos interesses daqueles que estão a comandar o Estado. Veja-se o exemplo dos povos indígenas do Rio Branco (atual nordeste do Estado de Roraima), denominados de as muralhas dos sertões por Nádia Farage (1991), utilizados como discurso jurídico para legitimar o domínio brasileiro sobre as terras que estavam em litígio com a Coroa Britânica, disputa que só foi dirimida após a submissão à arbitragem ao pelo rei da Itália, em 1904. Tornou-se irônico que, tempos depois, os índios de Roraima, no século XVIII, usados como muralhas dos sertões, garantidores das fronteiras brasileiras, fossem vistos posteriormente como ameaças a essas mesmas fronteiras (CUNHA, 2013).

Dessa maneira, a luta pelo direito aos territórios não pode ser razão para se esvaziar a discussão em torno de outros direitos, também, renegados. O direito aos territórios e ao usufruto dos mesmos só é completo se associado aos demais direitos, dentre eles o que permita o exercício de uma educação diferenciada.

\footnotetext{
Não adianta proteger manifestações culturais de povos indígenas, quilombolas e de outros grupos sociais sem assegurar-lhes condições de sobrevivência física e culturais.

O multiculturalismo procura descrever a existência de uma multiplicidade de culturas no mundo, que coexistem e se interfluenciam tanto dentro como fora de um mesmo Estado-nação, e, como projeto político, aponta para a celebração ou reconhecimento dessas diferenças culturais. As versões emancipatórias do multiculturalismo se baseariam no reconhecimento da diferença e do direito à diferença e da construção de uma vida em comum além das diferenças (SANTILLI, 2007, p. 79-80).
}

\footnotetext{
No fim do ano de 1831, encontrava-me à margem esquerda do Mississipi, num lugar chamado Memphis, pelos europeus. Enquanto me achava naquele lugar, surgiu um bando numeroso de Choctaws (os franceses da Louisiana chamam-lhe Chactas); aqueles selvagens deixavam a sua terra e procuravam passar para a margem direita do Mississipi, onde tinham esperança de encontrar um asilo que o governo americano thes prometia. Estávamos já no coração do inverno, e o frio, naquele ano, era desusadamente severo; a neve endurecera a terra e o rio carregava blocos enormes de gelo. Os índios levavam consigo as suas famílias; arrastavam atrás de si feridos, doentes, crianças que acabavam de nascer e velhos que iam morrer. Não tinham nem tendas, nem carros, mas apenas algumas provisões e armas. Vi-os embarcar para atravessar o grande rio, e aquele espetáculo solene jamais deixará a minha lembrança. Não se ouviam, no meio daquela multidão reunida, nem soluços nem queixas; calavam-se. As suas infelicidades eram antigas e sentiam que eram irremediáveis. Os índios tinham já todos entrado no navio que os deveria levar; os seus cães ainda continuavam na margem; quando aqueles animais viram, afinal, que se iriam afastar para sempre, soltaram juntos uivos terríveis e, lançando-se junto às águas geladas do Mississipi, seguiram a nado seus senhores. A expulsão dos índios hoje em dia muitas vezes se faz de maneira regular e por assim dizer literalmente legal" (TOCQUEVILLE, 1987, p. 249).
} 
Revista da Faculdade de Direito-RFD-UERJ - Rio de Janeiro, n. 31, jun. 2017

Dessa maneira, a educação, na atual ordem, alicerçada em um ensino que tem como princípios regentes a liberdade de aprender, ensinar, pesquisar, a divulgação do pensamento, da arte e do saber, o pluralismo de idéias e de concepções pedagógicas (art. 206, II, e III, da CF) não pode se restringir a fontes formais de transmissão do conhecimento, tampouco se limitar aos anseios da maioria da população, devendo estender-se, de forma indistinta e diferenciada, aos povos indígenas.

Como se percebe, o direito a uma educação diferenciada é conquista tributada à Constituição Federal de 1988, que assegurou às comunidades indígenas a utilização de suas línguas maternas e processos próprios de aprendizagem ( $\$ 2^{\circ}$, do art. 210), sendo variante do multiculturalis mo ${ }^{\S \S \S \S \S \S .}$

Diogo Alfonso Iturralde Guerrero (2006) argumenta que o direito à educação diferenciada não se realiza de maneira isolada, fazendo parte de um conjunto de direitos que os povos vêm conquistando e exercendo, sendo, ainda, uma peça central no campo dos direitos culturais e estando intimamente ligado ao direito, à língua e as suas consequiências.

É de se lembrar que, o vigente Estatuto do Índio, Lei $\mathrm{n}^{\circ} 6.001$, de 19 de dezembro de 1973, contraditoriamente, ao mesmo tempo em que diz assegurar o respeito ao patrimônio cultural das comunidades indígenas, seus valores artísticos e meios de expressão (art. 47), simplesmente, pretendeu impor o sistema educacional em vigor no país aos povos indígenas (art. 48).

Desrespeitando, os valores tradicionais dos índios, o Estatuto do Índio diz que a educação do índio seria orientada para a integração na inconceituada "comunhão nacional", mediante processo de gradativa compreensão dos problemas gerais e valores da sociedade nacional (art. 50). O Estatuto refletia uma compreensão da questão indígena, de progressiva integração a sociedade nacional que não mais se coaduna com os debates contemporâneos de autonomia e autodeterminação.

No entanto, à semelhança da Educação Ambiental não-formal, ou seja, aquela constituída por um conjunto de práticas e ações de natureza educativa, cujos objetivos são a sensibilização da coletividade sobre as questões ambientais e a sua organização na defesa da

$\S \S \S \S \S \S$ “O multiculturalismo permeia claramente o art. 210, parágrafo $2^{\circ}$, que estatui que o 'ensino fundamental regular será ministrado em língua portuguesa, assegurada às comunidades indígenas também a utilização de suas línguas maternas e processos próprios de aprendizagem'. Tal dispositivo revela a preocu pação do constituinte com a transmissão das línguas indígenas às novas gerações, e é complementado pelo artigo 215 , parágrafo $1^{\circ}$, que obriga o Estado a proteger as manifestações culturais dos povos indígenas e de outros grupos integrantes da sociedade brasileira" (SANTILLI, 2007, p. 84). 
qualidade do meio ambiente (MINC, 2008), a educação indígena deve ser voltada para o cultivo de um saber prático e de utilidade local. Aliás, em se tratando de questão ambiental, os povos indígenas souberam se adaptar ao ambiente natural em que estavam inseridos, apesar das críticas rasteiras que o senso comum leva a se fazer sobre o seu modo de produção.

\begin{abstract}
O método da agricultura itinerante, apesar de suas deficiências, é o mas apropriado para o ambiente, superando as técnicas de agricultura intensiva que predominam nas regiões temperadas [...] O ponto a ser acentuado aqui é que a agricultura itinerante não constitui um método de cultivo primitivo e incipiente, tratando, ao contrário de uma técnica especializada que se desenvolveu em resposta às condições específicas de clima e solo tropicais (MEGGERS, 1987, p. 47-50).
\end{abstract}

Ademais, estando os povos indígenas situados em espaços de constante contato entre recursos naturais e patrimônio cultural, cabe ao Estado, com o respeito da sociedade e participação dos interessados, a promoção de uma educação ambiental e conscientizada para a preservação do meio ambiente (art. 225, $\S 1^{\circ}$, VI, da CF) e das manifestações culturais (art. $215, \S 1^{\mathrm{o}}$, da CF).

A educação diferenciada para os povos indígenas significa respeito ao sistema tradicional de vida desses povos. Cite-se, por exemplo, que, no ano de 1993, em Manágua, Nicarágua, foi realizada a Primeira Reunião de Cúpula dos Povos Indígenas, que definiu diversas linhas de atuação, chamando atenção a preocupação dos mesmos com a questão educacional (MINC, 2008), dentre os quais: a) que os conteúdos da educação fossem baseados na filosofia e na cosmovisão indígenas, evitando o colonialismo cultural; b) que a espiritualidade, as línguas, as tradições, a sabedoria e os costumes indígenas fossem incluídos na educação; c) que a história dessas nações fosse escrita pelos próprios indígenas; d) que se impulsionassem a coordenação de grupos de pesquisa social e econômica, grupos de tecnologia alternativa e ambientalista para gerar programas de desenvolvimento integral e ecológico; e) que se fizesse um projeto alternativo global fundado na autodeterminação solidária e ; f) que fosse lançado um brado de resistência: "arrancaram nossas frutas, cortaram nossos galhos, queimaram nosso tronco, mas não puderam matar nossas raízes".

Edson Damas da Silveira (2008, p. 84), ao discorrer sobre a ética ambiental emancipatória na Amazônia, lança interessantes considerações a respeito do aprendizado dos povos tradicionais:

Sem embargo dessas primeiras observações, é possível, então, firmarmos a premissa de que as comunidades tradicionais Amazônicas - emdiferentes graus de 


\begin{abstract}
sustentabilidade - mantêm um relacionamento mais harmonioso com a natureza que a civilização hegemônica do Ocidente [...]

Esse novo senso comum se confunde com uma moralidade que privilegia os saberes naturais e que aprende com o ciclo intermitente e complexo da natureza. Há nele um nítido regresso às coisas simples, nas quais se valoriza o conhecimento empírico, aquele captado primitivamente pelos nossos sentidos e que foi desvalorizado pelo conhecimento frio e calculista da ciência moderna.
\end{abstract}

Não é de se esquecer que a Constituição assegurou aos índios a utilização de suas línguas maternas e processos próprios de aprendizagem (art. 210, $\S 2^{\circ}$ ). No entanto, a garantia do direito a educação não pode representar uma forma de sufocamento da cultura e dos padrões éticos dos povos indígenas, como se houvesse, ainda, a intolerável concepção de chamá-los à 'comunhão nacional' através dos processos de aprendizagem.

Em relação aos índios, a educação é, eminentemente, diferenciada, pois o seu objetivo não é de instruir os índios para que saiam de um suposto atraso, mas o de oferecer aos mesmos uma instrução compatível com a sua cultura, crenças e tradições, em processo de diálogo.

Nesse contexto, quando se pensa em educação dos povos indígenas, não se vislumbra uma educação uniforme para todos os povos indígenas, pois os povos indígenas não constituem uma única categoria ${ }^{* * * * * * * * *}$.

Contrariamente às medidas afirmativas, que têm caráter transitório (ROULAND, 2004), o direito à educação diferenciada tem caráter permanente, pois leva em consideração os direitos culturais dos povos indígenas, e estes direitos refletem a própria essência do povo, tais como a língua, os mitos de origem, a arte, os saberes e a religião, cuja roupagem os diferencia dos outros (SOUZA FILHO, 2004).

Também, de forma diversa ao previsto no Estatuto do Índio, a educação dos povos indígenas, assim como outras populações tradicionais, não deve ter como objetivo a promoção de nivelamento igualitário, mas a manutenção da diferença, pois, para os indígenas, semelhantemente a outras populações que se fixaram na Amazônia, a igualdade pode significar o direito de ser diferente, implicando diversidade a ser observada e respeitada por todos (SILVEIRA, 2008), principalmente pelo Estado, ao instituir as políticas educacionais que lhes alcançarão.

\footnotetext{
********** "Esta determinação de considerar todos os povos indígenas numa única categoria é uma constante na história das relações dos colonizadores como os povos indígenas tendo gerado o termo único 'índio' em contraposição ao nome de cada uma das nações, e a 'língua-geral', pela qual os missionários queriam que todos os povos os entendessem e se entendessem entre si e, principalmente, entendessem a 'boa nova' da evangelização. A dimensão do preconceito, discriminação e etnocentris mo está clara nesta tentativa de unificar a religião, a língua, a cultura e o Direito, negando a diversidade" (SOUZA FILHO, 2004, p. 73).
} 
A educação diferenciada tem como dimensão o contato intercultural em que se instaura o conflito e a luta pela apropriação e reconstrução do espaço dominante, filtrados e reinterpretados a partir de categorias próprias (WEIGEL, 2000).

Nesse contexto, qualquer tentativa de sonegar uma educação diferenciada aos índios representa retrocesso histórico, intolerável no momento atual. Thaís Luzia Colaço (2006, p. 111-112), ao tratar das fundações jesuíticas do Paraguai, lembra o quanto era perversa a tentativa de educar os índios.

\begin{abstract}
Os caciques deveriam ser cativados para depois serem cristianizados. Observavam como deveria ser feita a catequização de crianças e adultos. Recomendavam a fundação de escolas para meninos, onde ensinava o catecismo, a ler, a escrever, a cantar e a tocar instrumentos musicais. Os melhores alunos deviam ser recompensados. Davam instruções sobre batismo, o casamento, a extrema-unção e os enterros. Previam um sistema de fiscalização da população e formas e tipos de castigos.
\end{abstract}

A educação diferenciada é voltada para a construção de um saber prático, formação de uma cultura de respeito à conservação dos recursos naturais e que prima pelo desenvolvimento sustentável. Aliás, a Lei $\mathrm{n}^{\circ}$ 9.795/99, que instituiu a Política Nacional de Educação Ambiental, determina, no inciso V, do parágrafo único, do art. 13, que o Poder Público, incentivará a "sensibilização ambiental das populações tradicionais ligadas às

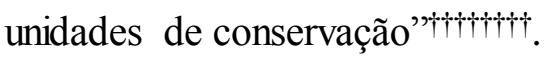

No plano legislativo, atendendo aos anseios dos povos indígenas, o Estado brasileiro reconheceu, no plano normativo, o direito à educação diferenciada, através do Decreto $\mathrm{n}^{\circ}$ 6.861, de 27 de maio de 2009, que "dispõe sobre a Educação Escolar Indígena, define sua organização em territórios etnoeducacionais, e dá outras providências".

$\mathrm{O}$ artigo $1^{\circ}$ (primeiro) do decreto dispõe que a educação escolar indígena será organizada com a participação dos povos indígenas, observada a sua territorialidade e respeitando suas necessidades e especificidades.

Já o artigo $2^{\circ}$ (segundo) apresenta os objetivos da educação escolar indígena, quais sejam: valorização das culturas dos povos indígenas e a afirmação e manutenção de sua

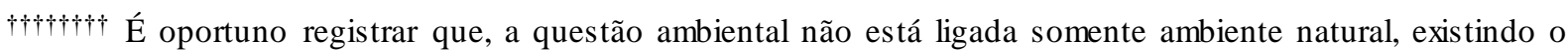
ambiente cultural, ao lado dos ambientes natural e artificial (SILVA, 2007), pois o ambiente cultural consiste em um conjunto de bens móveis ou imóveis, materiais ou imateriais, decorrentes tanto da ação da natureza e da ação humana como da harmônica ação conjugada da natureza e da pessoa humana, de reconhecidos valores vinculados aos diversos e progressivos estágios dos processos civilizatórios e culturais de grupos e povos; integrado de elementos básicos da civilização e da cultura dos povos, o patrimônio cultural, em seu s reconhecidos valores individuais ou em conjunto, constitui complexo de bens juridicamente protegidos em todos os níveis de governo, tanto nacional como internacional (FREITAS, 2005). 
Revista da Faculdade de Direito-RFD-UERJ - Rio de Janeiro, n. 31, jun. 2017

diversidade étnica; fortalecimento das práticas socioculturais e da língua materna de cada comunidade indígena; formulação e manutenção de programas de formação de pessoal especializado, destinados à educação escolar nas comunidades indígenas; desenvolvimento de currículos e programas específicos, neles incluindo os conteúdos culturais correspondentes às respectivas comunidades; elaboração e publicação sistemática de material didático específico e diferenciado; e afirmação das identidades étnicas e consideração dos projetos societários definidos de forma autônoma por cada povo indígena.

$\mathrm{O}$ artigo $3^{\circ}$ (terceiro), por sua vez, reconhece às escolas indígenas a condição de escolas com normas próprias e diretrizes curriculares específicas, voltadas ao ensino intercultural e bilíngue ou multilíngue, gozando de prerrogativas especiais para organização das atividades escolares, respeitado o fluxo das atividades econômicas, sociais, culturais e religiosas e as especificidades de cada comunidade, independentemente do ano civil.

Reconhecendo que os povos indígenas se constituem por comunidades que extrapolam as questões burocráticas do Estado brasileiro, o Decreto organizou a Educação Escolar Indígenas nos chamados territórios etnoeducacionais, da seguinte maneira:

\footnotetext{
Art. $6^{\circ}$. Para fins do apoio de que trata o art. 5o, a organização territorial da educação escolar indígena será promovida a partir da definição de territórios etnoeducacionais pelo Ministério da Educação, ouvidos: [...]

Parágrafo único. Cada território etnoeducacional compreenderá, independentemente da divisão político-administrativa do País, as terras indígenas, mesmo que descontínuas, ocupadas por povos indígenas que mantêm relações intersocietárias caracterizadas por raízes sociais e históricas, relações políticas e econômicas, filiações lingüísticas, valores e práticas culturais compartilhados.
}

Dessa maneira, o decreto em referência, evidentemente, representa um grande avanço para o reconhecimento dos direitos dos povos indígenas, consagrando o direito a uma educação diferenciada do sistema comum, objetivando atender ao saber prático dos mesmos.

Diante disso, reconhecendo o Estado, no plano formal o direito à educação diferenciada, caberá aos povos indígenas, individual, em grupo ou através dos órgãos estatais competentes, cobrar, no plano prático, que o mesmo Estado ofereça as condições possíveis para que tal direito não seja uma mera promessa sem cumprimento. 


\section{IV - CONSIDERAÇÕES FINAIS}

O trabalho analisou, sob o viés jurídico, a finalidade do direito à educação diferenciada dos povos indígenas em um contexto constitucional que garante o direito à diferença.

Sob a perspectiva histórica, o trabalho, baseado nas ideias de Pierre Bourdieu discutiu a chamada razão imperialista e a questão da dominação simbólica, debatendo a questão do sistema de ensino, utilizado para dominar os povos indígenas, dando invisibilidade as suas identidades culturais.

Com a Constituição Federal de 1988, sob uma nova perspectiva, os direitos indígenas, assim como seus modos de fazer, de criar e de viver, passaram a deter natureza comunitária e não costumando ser objeto de partilha, ou seja, correlacionam-se de forma mútua e são interligados entre si - territórios, saberes, educação, saúde, cultura e natureza.

As formas de vida dos povos indígenas investidas de conteúdo próprio estão dissociadas da forma de viver dos demais indivíduos que compõem a sociedade nacional. É esta distinção que lhes garante direitos diferenciados. Em termos de análise, o princípio da isonomia é o ponto de partida, pois se reconhece a igualdade entre sujeitos, diferentemente de um outro período em que a igualdade era a meta a ser alcançada.

Nesse contexto, a preocupação com o direito à educação diferenciada dos povos indígenas decorre do fato de os mesmos, atualmente, sabedores de seus direitos, têm atuado nas esferas discursivas formais e informais apresentando as suas reivindicações, inclusive o respeito à manutenção de suas tradições, o que perpassa pelo respeito e garantia do direito a terem um processo educacional que garanta a diferença e a pluralidade de seus modos de vida.

Analisou-se, dessa forma, a existência de um direito constitucional à educação diferenciada, procurando-se correlacionar essa educação, voltada, eminentemente, para o cultivo de saber prático e de respeito a um ambiente equilibrado e sustentável, como uma das formas de sobrevivência dos povos indígenas, e verificou-se que, juridicamente, o reconhecimento do direito aos territórios, conquanto importante, por si só, não lhes garante os objetivos da Constituição.

Desse modo, discutiu-se qual a finalidade do direito à educação diferenciada dos povos indígenas, realizando-se uma análise transversal, aproximando o direito de outros ramos da pesquisa científica, pois a falta de estudos acarreta uma interpretação 
completamente distorcida da legislação que ampara a educação diferenciada, deixando o direito aquém de outros ramos do conhecimento, tais como a antropologia e a pedagogia, bastantes pródigas em discussões sobre o tema.

Por fim, analisou-se o Decreto $\mathrm{n}^{\mathrm{o}}$ 6.861, de 27 de maio de 2009, que "dispõe sobre a Educação Escolar Indígena, define sua organização em territórios etnoeducacionais, e dá outras providências", que representou o reconhecimento pelo Estado brasileiro dos anseios dos povos indígenas em relação ao direito à educação diferenciada.

\section{V- REFER ÊNCIAS}

ALMEIDA, Alfredo Wagner Berno de. Terra das Línguas. Lei Municipal de Oficialização de Línguas Indígenas São Gabriel da Cachoeira. Manaus: PPGSCA-UFAM/F FORD, 2007.

BARRETO, Helder Girão. Direitos indígenas: vetores constitucionais. Curitiba: Juruá, 2004.

BOURDIEU, Pierre. Escritos de educação. 2. ed. Petrópolis. Vozes: 1998.

A força do direito. Elementos para uma sociologia do campo jurídico. O Poder simbólico. Lisboa: Difel, 1989, p. 209-254.

; WACQUANT, Loic. A astúcia da razão imperialista. O mistério do mistério.

Rio de Janeiro: Editora Revan, 2005, p. 209-230.

CALDEIRA, José de Ribamar Chaves. A criança e a mulher tupinambá. São Paulo: Scortecci, 2000.

CLAVERO, Bartolomé. Descolonización, derechos humanos, diversidade de cultural. In: WILHELMI, Marco Aparício. Los derechos de los pueblos indígens a los recursos naturales y al território. Barcelona: Içaria edicion, 2011, p. 31-66.

COLAÇO, Thaís Luzia. Incapacidade indígena: tutela religiosa e violação do direito guarani nas missões jesuíticas. Curitiba: Juruá, 2006.

CUNHA, Manuela Carneiro da. Índios no Brasil: história, direitos e cidadania.São Paulo: Claro Enigma, 2012. 
Revista da Faculdade de Direito-RFD-UERJ - Rio de Janeiro, n. 31, jun. 2017

FARAGE, Nádia. As muralhas dos sertões: os povos indígenas no Rio Branco e a colonização. Rio de Janeiro: Paz e Terra - ANPOCS, 1991.

FERREIRA, Alexandre Rodrigues. Viagem filosófica pelas Capitanias do Grão-Pará, Rio

Negro, Mato Grosso e Cuiabá. 2. ed. Estudo introdutório de Adelino Brandão. Manaus:

Editora Valer, 2008.

FREIRE, Paulo. Pedagogia do oprimido. 57. ed. Rio de Janeiro: Paz e Terra, 2014.

FREITAS, Vladimir Passos. A Constituição Federal e a efetividade das normas ambientais. 3. ed. São Paulo: Revista dos Tribunais, 2005.

GIRAUDO, Laura (ed.). Ciudadania y derechos indígenas em América Latina: poblaciones, estados y orden internacional. Madrid: Centro de Estúdios Politicos y Constitucionales, 2007. Entre rupturas y retornos: la nueva question indígena em America Latina, p. 7-57.

GUERRERO, Diego Alfonso Iturralde. Direitos culturais indígenas e educação intercultural bilíngüe - a situação na América Central. In: HERNAIZ, Ignacio (org). Educação na diversidade: experiências e desafios na educação intercultural bilíngüe. Brasilia: UNESCO, Secad/MEC, 2006.

HERRERA FLORES, Joaquim (ed.). Hacia uma visión compleja de los derechos humanos. El vuelo de Anteo. Derechos humanos y critica de la rázon liberal. Bilbao: Editorial Desclée Brouwer, 2000, p. 19-78.

YRIGOYEN FAJARDO, Raquel Z. El horizonte del constitucionalismo pluralista: del multiculuralismo a la descolonización. In: RODRÍGUEZ GARAVITO, César. El derecho en América Latina: un mapa para el pensamiento jurídico del siglo XXI. Buenos Aires: Siglo Veintiuno Editores, 2011, p. 139-159.

LIMA, André; BENSUSAN, Nurit (orgs.). Quem cala consente?: subsídios para a proteção dos conhecimentos tradicionais. São Paulo: Instituto Socioambiental, 2003.

MARTÍ I PUIG, Salvador. Sobre la emergencia e impacto de los movimientos indígenas em las arenas políticas de América Latina: algunas claves interpretativas desde lo local y lo 
Revista da Faculdade de Direito-RFD-UERJ - Rio de Janeiro, n. 31, jun. 2017

global. In: WILHELMI, Marco Aparício. Los derechos de los pueblos indígens a los recursos naturales y al território. Barcelona: Icaria edicion, 2011, p. 67-102.

MEGGERS, Betty J. Amazônia: a ilusão de um paraíso. Tradução de Maria Yedda Linhares. Belo Horizonte - São Paulo: Editora Itatiaia - Editora da Universidade de São Paulo, 1987.

MINC, Carlos. Ecologia e cidadania. 2. ed. São Paulo: Moderna, 2008.

NADER, Laura; MATTEI, Ugo. Pilhagem: quando o Estado de Direito é ilegal. São Paulo: Martins Fontes, 2013.

PROJETO PEDAGÓGICO DO CURSO DE GESTÃO TERRITÓRIAL. Núcleo Insikiran de Formação Superior Indígena da Universidade Federal de Roraima (UFRR). Boa Vista (RR), s/d.

RIBEIRO, Darcy. O povo brasileiro: a formação e o sentido do Brasil. 2. ed. São Paulo: Cia. das Letras, 2003.

ROULAND, Nobert (org.). Direito das minorias e dos povos autóctones. Tradução de Ane Lize Spaltemberg. Brasilia: Editora da Universidade de Brasilia, 2004.

SANTILLI, Juliana. Socioambientalismo e novos direitos: proteção jurídica à diversidade biológica e cultural. São Paulo: Peirópolis - ISA, 2007.

SOUSA SANTOS, Boaventura de; NUNES, João Arriscado. Introdução: para ampliar o cânone do reconhecimento, da diferença e da igualdade. In: SOUSA SANTOS, Boaventura de (org.). Reconhecer para libertar: os caminhos do cosmopolitismo multicultural. Rio de Janeiro: Civilização Brasileira, 2003.

SOUZA FILHO, Carlos Frederico Marés de. Multiculturalismo e direitos coletivos. In: SOUSA SANTOS, Boaventura de (org.). Reconhecer para libertar: os caminhos do cosmopolitismo multicultural. Rio de Janeiro: Civilização Brasileira, 2003.

O renascer dos povos indígenas para o direito. Curitiba: Juruá, 2004.

SHIRAISHI NETO, Joaquim. O pluralismo como valor fundamental: A co-oficialização das línguas Nheegati, Tukano e Baniwa, à língua portuguesa, no município de São Gabriel das 
Revista da Faculdade de Direito-RFD-UERJ - Rio de Janeiro, n. 31, jun. 2017

Cachoeiras, Estado do Amazonas.” In: ALMEIDA, Alfredo Wagner (org). Terra das

Línguas:Lei Municipal de Ofi -cialização de Línguas Indígenas, São Gabriel da Cachoeira, Amazonas. Manaus: PPGSCA-UFAM/FUND. FORD, 2007, p. 71-74.

SILVA, José Afonso da. Curso de direito constitucional positivo. 22. ed. São Paulo: Malheiros, 2003.

SILVA, José Afonso da. Direito ambiental constitucional. 6. ed. São Paulo: Malheiros, 2007.

SILVEIRA, Edson Damas da. Socioambientalismo amazônico. Curitiba: Juruá: 2008.

TOCQUEVILLE, Alexis. A democracia na América. 4. ed. Tradução e notas de Neil Ribeiro da Silva. Belo Horizonte - São Paulo: Editora Itatiaia - Editora da USP, 1998.

WALSH, Catherine. Interculturalidad critica y (de)colonialidad. Quito: Abya Yala, 2012, p. $110-133 ; 135-152$.

WEIGEL, Valéria Augusta Cerqueira de Medeiros. Escolas de branco em malokas de índios. Manaus: Editora da Universidade Federal do Amazonas, 2000. 